\title{
Challenging bias
}

\section{Alison Williams}

Implicit or unconscious bias happens by our brains making incredibly quick judgments and assessments of people and situations without us realising. Our biases are influenced by our background, cultural environment and personal experiences. We may not even be aware of these views and opinions, or be aware of their full impact and implications. (Equality Challenge Unit)

Apart from being struck by the many graffiti versions of: "A woman needs a man like a fish needs a bicycle", the feminist consciousnessraising 1970 completely passed me by. I understood the phrase 'unconscious bias' but never really applied it to myself. Then I had the great good fortune to hear Jesse Jackson speak on the evening he was awarded an honorary degree by the University of Edinburgh. He said, talking of racism: "I don't blame people for their unconscious bias. The people I do blame are those who become aware of their bias and do nothing about it."

The following week I attended a research seminar led by three young women researchers who had flown up from London for the day. My first thought as I walked into the room was: "What can these young slips-of-girls possibly know?" It became very clear very soon that with their two PhDs and a degree in neuroscience between them they knew a lot, and were generous in their sharing.
And it also became clear to me, with Jesse Jackson's words ringing in my ears, that I had become aware of two of my own hitherto unconscious biases, age and gender, mixed up together. This recipe sets out what I did, and continue to do, to challenge and change any personal biases as I become aware of them. As bell hooks says: "[T] he problem is sexism. [...] all of us, female and male, have been socialized from birth on to accept sexist thought and action. As a consequence, females can be just as sexist as men" (hooks 2000, p. viii).

\section{Ingredients}

- A powerful stimulus.

- A whoopsie moment.

- An unconscious bias (alive and kicking and very nasty).

- A notebook and pencil and lots of awkward questions.

- Laughter (fresh, not canned).

- The 3 As (Awareness - AcceptanceAction) and some awkward questions.

\section{Method}

1. Awareness. First catch your whoopsie moment. Whoopsie moments feel deeply uncomfortable. Everyone has their own set of awareness triggers, mental, physical and - most powerful - emotional. I know l'm having a whoopsie moment when I find myself 


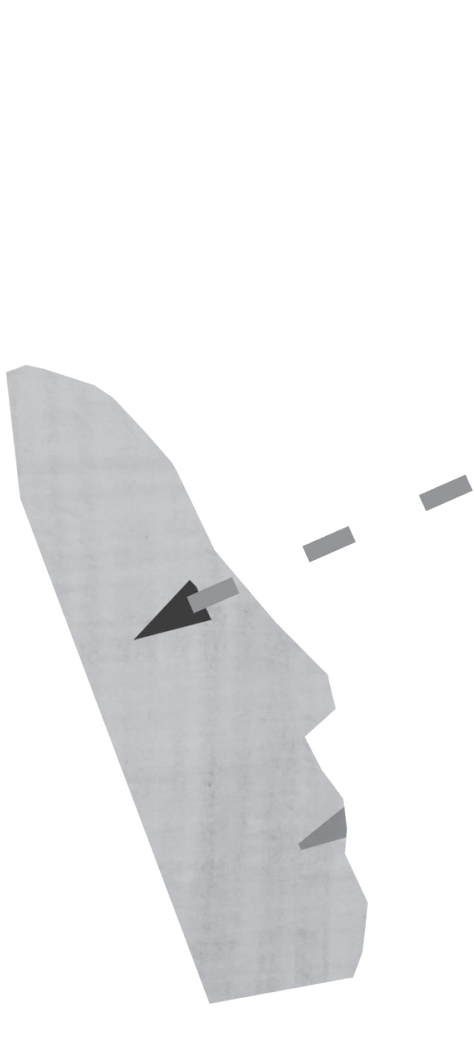

being critical, or defensive, or snippy, or using phrases like: "They make me feel/ do/say". An unconscious bias can be slippery and devious when challenged.

Awkward question: What are your emotional/mental/physical responses to a whoopsie moment? Do you go red? Get aggressive? Point the finger? Stop collaborating? Do you try to prove that you are in every way superior to the person/people who are making you feel (watch out for that one- no one makes us feel, we do it all on our own) uncomfortable?

2. Next, dissect your whoopsie: lay it out on the kitchen table (or board room, or desk, or lab) and examine carefully. There will be an unconscious bias hiding in the middle of it. Now stop and ask yourself what it is that you feel uncomfortable about. Doing this is easier if you keep

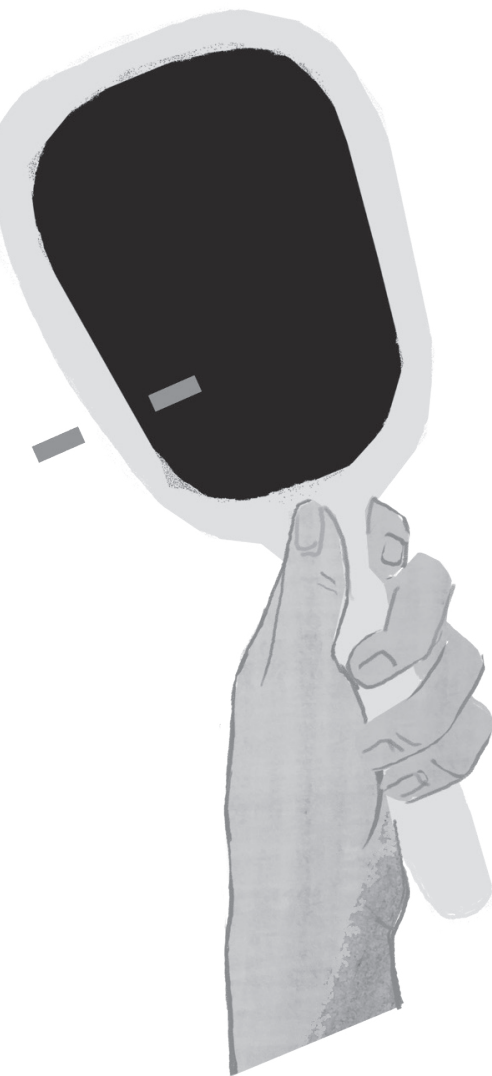

your mouth shut and your ears open, and remember to breathe. And when you catch yourself at it, laugh!

Awkward question: What could you do to give yourself time and permission to look at your whoopsie and find the bias?

3. Acceptance. The next stage of this recipe is Acceptance. I can't do something about my bias and make changes to my own behaviour and responses until I accept that something is wrong. I need to mull things over: a good walk, or talking it over with a trusted friend or colleague really helps. And then I ask myself: "What can I do about it right now?" and "What can I do to make sure that it doesn't happen again?"

Awkward question: What's your process for accepting there's a bias in the centre of your whoopsie? 
4. Action. Now your unconscious bias has been caught, laid out, examined and simmered for as long as it takes to be accepted, deal with it in the moment: keep your mouth shut and your mind open, keep breathing and keep smiling. Mentally challenge the bias - it isn't worthy of you. Resist any attempts that the bias makes to drag you into justifying it and prolonging its miserable life. Remember to laugh at it, and at yourself. Now, make sure it doesn't happen again.

\section{Take a small unused notebook (A6} conference freebie is ideal) that can tuck into a pocket or bag. Start to record your whoopsie moments, and note how you respond, internally and externally. It's powerful to see it laid out on the page, and cathartic too. The funny thing about unconscious biases is that they hate the light. A good burst of exposure and they start to shrivel.

\section{Cook's tips}

This recipe is written from my IAD freebie notebook. I continue to use it to keep myself honest. Biases can take a while to exorcise and changing my thinking takes time. Now I have got to the stage when I mostly catch myself at it, and a few moments of laughing at myself helps the process along. Since starting my whoopsie journal, I have found myself making fewer and fewer entries. And having better and better conversations with more and more people that are nourishing, thoughtprovoking and keep us all coming back for more. 